\title{
In Vitro Evaluation of Electrospun Polysaccharide Based Nanofibrous Mats as Surgical Adhesion Barriers
}

\author{
Serife Safak ${ }^{1}$, Ozgur Vatan², Nilufer Cinkilic², Esra Karaca ${ }^{3}$ \\ ${ }^{1}$ Namık Kemal University, Corlu Faculty of Engineering, Department of Textile Engineering, 59860, Corlu, Tekirdag, TURKEY \\ ${ }^{2}$ Bursa Uludag University, Faculty of Arts and Sciences, Department of Biology, 16059, Gorukle, Bursa, TURKEY \\ ${ }^{3}$ Bursa Uludag University, Faculty of Engineering, Department of Textile Engineering, 16059, Gorukle, Bursa, TURKEY
}

Corresponding Author: Şerife Şafak, ssafak@nku.edu.tr

\begin{abstract}
Post-operative adhesions are one of the most important problems faced by patients and surgeons. In this study, nanofibrous mats were produced as novel surgical adhesion barrier from polysaccharidebased polymers, hyaluronic acid, carboxymethyl cellulose and sodium alginate, via electrospinning. The produced nanofibrous mats were crosslinked with 1-ethyl-3-(3-dimethylaminopropyl) carbodiimide hydrochloride and N-hydroxysulfosuccinimide. Furthermore, the morphology, in vitro degradation, cytotoxicity and cell adherence potentials of the nanofibrous mats aimed to be used as adhesion barriers were evaluated and compared with a commercial adhesion barrier. Results of the in vitro experiment showed that the nanofibrous mats have maintained their physical structures during the critical period for adhesion formation, and had non-adherent cell feature and non-cytotoxic nature required for an ideal adhesion barrier.
\end{abstract}

\author{
ARTICLE HISTORY \\ Received: 02.04.2019 \\ Accepted: 04.03.2020
}

\section{KEYWORDS}

Nanofiber, adhesion barrier, polysaccharide polymers, in vitro

\section{INTRODUCTION}

Nanofibers are defined as fibers with diameters less than one micron [1,2]. There are many techniques for the production of nanofibers: electrospinning [3,4], selfassembly $[5,6]$, phase separation $[7,8]$, and template synthesis [9,10]. Among these techniques, only electrospinning is versatile, simple, continuous process that can produce large scale nanofibers from wide range of materials for industrial applications.[11-13]. As a production method, electrospinning is utilized to form nanofibers from melted or dissolved polymer using high electric voltage [3,4]. Electrospun nanofibers have many good properties which require for biomedical applications such as high surface-to-volume ratios, small pore sizes, high porosity and superior mechanical properties $[11,14]$. Due to these properties electrospun nanofibers, they are used in biomedical applications such as medical prosthesis (artificial blood vessels and artificial organ applications), wound dressings, drug delivery systems, tissue scaffolds and skin care products [3, 4, 11-16].

Polysaccharide-based polymers have been widely studied as biomaterials for a variety of biomedical applications including drug delivery and regenerative medicine. Because of their biochemical similarity with human extracellular matrix (ECM) components, these polymers are readily recognized and accepted by the body [17]. Extracellular matrix (ECM) is a three-dimensional macromolecular network that provides structural and biochemical support for the cell survival, adhesion, proliferation, cellular communication and differentiation [18-20]. Native ECM composed of matrix proteins, glycoproteins, and glycosaminoglycans [21]. Glycosaminoglycans (GAGs) are highly sulfated, linear polysaccharides and covalently linked to a core protein to form proteoglycans [22]. Proteoglycans provide resitance to compressive forces and have key roles in regulating cell morphology, differentiation, and function [21]. Polysaccharides providing a hydrated space for the diffusion of nutrients and mats as surgical adhesion barriers. Tekstil ve Konfeksiyon, 30(2), 99-107. 
metabolites to and from the cell [23]. The list of polysaccharides used commonly for a variety of biomedical applications includes cellulose, carboxymethyl cellulose, chitin/chitosan, starch, alginate, hyaluronic acid, pullulan, guar gum, and glycosaminoglycan [17].

Hyaluronic acid (HA) is one of the major components of the extracellular matrix between cells in various living organisms such as cartilage, joint fluid, skin and umbilical cord. Its high viscoelasticity, non-toxic properties, and ability to absorb water due to high molecular weight and negatively charged nature, make it possible for usage in cosmetic, biomedical and food industries. Due to its biocompatibility and biodegradability, HA polymer has been used especially in tissue engineering applications in the form of gel and/or film [24-27].

Anionic and water-soluble carboxymethyl cellulose (CMC) polymer is produced with carboxylation of the cellulose and belongs to the group of cellulose ethers. CMC is used as a binder, blowing, gelling, adhesive and stabilizer agent in textile, paper, pharmaceutical, paint, cosmetic, ceramic and food industries. The main reasons for choosing CMC as an additive in these fields of use are that it is a physiologically inert, water-soluble, non-toxic and biocompatible polymer having high water retention capacity. Also, CMC is compatible with colloids and has a bacterial resistance due to its high sodium content $[28,29]$.

Sodium alginate (NaAlg) is a natural polysaccharide derived from brown seaweed. NaAlg has been used in food, pharmaceutical, medical, textile and paper industries for many years. Recently, its utilization has increased, especially in biomedical and medical fields. The specific properties that facilitate wound healing of NaAlg, e.g., high moisture absorption and ion exchange abilities, excellent biocompatibility, and bleed inhibitor properties, make it a unique raw material in the production of high absorbent wound dressing [30, 31].

Adhesions are described as abnormal connections between organs that are not normally associated with each other and surrounded by the serous membrane, following injury or surgical operations. The main reasons of adhesions are surgical procedures. Adhesions are common after chest, heart and intra-abdominal operations. The main approaches proposed in the literature to prevent or reduce adhesion are divided into three categories: the development of surgical techniques, the use of anti-adherence drugs, and the separation of tissues during the healing process. Adhesion barriers allow the surfaces of the injured region to be separated from each other and freely heal and thus prevent the formation of adhesion. An ideal adhesion barrier should not affect wound healing but should be non-reactive, effective in the presence of body fluids and blood, easy to use, and biodegradable. Furthermore, it should not cause infection and inflammation, and it should be antibacterial and stable in the initial phase of adhesion formation, and then metabolized [32-35].
There are limited studies in the literature about the use of nanofibrous mats produced by the electrospinning method as adhesion barriers [36-40]. In these studies, poly (lacticco-glycolic acid) (PLGA), polycaprolactone (PCL), PCL/gelatin, poly-L-lactide acid (PLLA), polyethersulfone (PES), chitosan and calcium alginate nanofibrous mats were produced, and their performances were evaluated as adhesion barrier in vivo experiments. Only Dinanvard et al. [37] conducted in vitro experiments. In a few studies [4144], PLGA, PCL, hyaluronic acid (HA)/PCL nanofiber membranes loaded with drugs, plant extract or silver were produced and proposed as adhesion barriers. Furthermore, in most studies, the resulting nanofibrous mats were not compared with a commercial adhesion barrier.

Today, complete adhesion prevention problem remains unsolved and the search for an ideal adhesion barrier is still ongoing. In this study, electrospun nanofibrous mats were first produced from hyaluronic acid (HA), carboxymethyl cellulose (CMC) and sodium alginate (NaAlg) polymer blends to be used as adhesion barriers, and their performances were evaluated with in vitro experiments by comparing to a commercial adhesion barrier. The produced nanofibrous mats are novel in terms of the polymer blends used and have a potential to be alternative to commercial barriers in film form.

\section{MATERIAL AND METHOD}

\subsection{Materials}

HA polymer (Hyaluronic acid sodium salt from Streptococcus equi) with Mw of 1,500,000-2,000,000 g/mol and CMC polymer with $\mathrm{Mw}$ of 250,000 $\mathrm{g} / \mathrm{mol}$ were purchased from Sigma Aldrich (USA). NaAlg polymer, Cecalgum $^{\circledR}$ S1300, with a viscosity of 700-900 cPs was kindly supplied by Cargill (Turkey). Sodium hydroxide (NaOH, Sigma Aldrich) and dimethyl sulfoxide (DMSO, Merck) were obtained to be used as the solvents for electrospinning of HA polymer. Distilled water was used as the solvent for CMC and NaAlg polymers.

For the crosslinking process of the nanofibrous mats, 1ethyl-3-(3-dimethylaminopropyl) carbodiimide hydrochloride (EDC) with Mw of $191.70 \mathrm{~g} / \mathrm{mol}$ and Nhydroxysulfosuccinimide (NHS) with Mw of $115.09 \mathrm{~g} / \mathrm{mol}$ were obtained from Sigma Aldrich. The crosslinked nanofibrous mats were neutralized in ethanol (Merck). All the materials were used without further purification.

In vitro experiments, a commercially available adhesion barrier film (Seprafilm ${ }^{\circledR}$, Sanofi-Aventis) containing HA and CMC polymers was used to compare with the nanofibrous adhesion barriers produced in this study.

Human umbilical vein/vascular endothelial cell line HUVEC (CRL-1730, ATCC) and mouse subcutaneous connective tissue fibroblast cell line L-929 (CCL-1, ATCC) 
were used to investigate cytotoxicity and cell adherence behavior on the nanofibrous mats and Seprafilm. On the cell viability test applied to determine the cytotoxicity, 2,3bis(2-methoxy-4-nitro-5-sulfophenyl)-2H-tetrazolium-5carboxanilide (XTT) cell proliferation kit (Biological Industries, Israel) was used. Live cells were determined with trypan blue solution (Sigma Aldrich).

Phosphate-buffered saline (PBS) of $\mathrm{pH} 7.4$ for the degradation and cytotoxicity tests was purchased from PAN Biotech (Germany).

\section{Production of nanofibrous adhesion barriers}

In this study, nanofibrous mats aimed as adhesion barriers were produced from HA/CMC, HA/NaAlg and HA/CMC/NaAlg polymer blends by electrospinning (Table 1). CMC and NaAlg solutions were prepared by dissolving $\mathrm{CMC}$ and NaAlg polymers in distilled water at $80{ }^{\circ} \mathrm{C}$ for 8 h. The concentration of solutions was $2 \% \mathrm{w} / \mathrm{v}$. HA polymer was dissolved in a volume ratio of $4: 1 \mathrm{NaOH} / \mathrm{DMSO}$ solvent system at room temperature for $8 \mathrm{~h}$ and the prepared HA solution concentration was $12 \% \mathrm{w} / \mathrm{v}$. For the electrospinning, solutions of NaAlg, CMC and HA were blended in the volume ratio of $3 / 1$ (HA/CMC), 5/1 (HA/NaAlg) and 3/1/1 (HA/CMC/NaAlg). The blended solutions were stirred at room temperature for $2 \mathrm{~h}$ to provide a homogeneous solution.

Prepared polymer solutions were fed into a plastic syringe of $20 \mathrm{ml}$. A spinneret with an inner diameter of $530 \mu \mathrm{m}$ was used as the feeding unit and a cylinder rotating at $200 \mathrm{rpm}$ was used as the collector. The cylinder collector was covered with aluminum foil. To achieve a smooth and beadless nanofiber formation, voltage, flow rate of solution, and distance between the spinneret and the collector were adjusted for each polymer solution. All samples were produced from $20 \mathrm{ml}$ spinning solution to obtain uniformity. Electrospinning experiments were carried out at ambient conditions and temperature. The temperature range: $20-28{ }^{\circ} \mathrm{C}$, and $\mathrm{RH}$ range: $50-80 \% \mathrm{RH}$ were measured during electrospinning process. The process parameters of produced nanofibrous mats are given in Table 1.

\section{Crosslinking and sterilization}

HA, CMC and NaAlg are water-soluble polymers, and the resulting nanofibrous mats have low resistance to water and water vapor. This situation would lead to problems in practical applications of the nanofibrous mats as adhesion barriers [45]. Therefore, to improve their stability in water, an appropriate crosslinking process was required to apply on the electrospun mats.

EDC is a water-soluble, biocompatible and nontoxic crosslinking agent. EDC activates carboxyl groups in the polysaccharide molecules and forms ester bonds between hydroxyl and carboxyl groups. The non-inclusion of EDC in the cross-linked structure, i.e., not binding to polymer molecules, is particularly recommended for materials used in the biomedical field. NHS is a nontoxic, biocompatible and homo-bifunctional crosslinker used to activate carboxylic acid groups. When a normal carboxylic acid forms a salt with amines, the acids which are activated in the presence of NHS react with amines to give amides. EDC productivity increases in NHS presence. The use of EDC together with NHS causes a formation of hydrolysisresistant and non-rearrangeable intermediates [46-49].

The crosslinking medium was prepared by mixing EDC (80 $\mathrm{mM})$ and NHS (100 mM) crosslinking agents of an equal ratio in ethanol of $20 \mathrm{ml}$. The HA/CMC, HA/NaAlg and $\mathrm{HA} / \mathrm{CMC} / \mathrm{NaAlg}$ nanofibrous mats were immersed in crosslinking medium at room conditions for $24 \mathrm{~h}$. After crosslinking, the mats were washed in ethanol for removing unbound crosslinking agents and then dried in an incubator at $37^{\circ} \mathrm{C}$ for $12 \mathrm{~h}$.

Before in vitro experiments, the crosslinked electrospun mats were sterilized with ethylene oxide gas at $55^{\circ} \mathrm{C}$ for $4 \mathrm{~h}$ and aerated for $8 \mathrm{~h}$.

\section{Characterization}

Surface morphologies of the nanofibrous mats and the commercial adhesion barrier (Seprafilm) were characterized by Scanning Electron Microscopy (SEM, Carl Zeiss AGEVO $40 \mathrm{XVP}$ ). The samples were coated with a thin layer of gold-palladium before analysis. The nanofiber diameter distributions were determined by using ImageJ software (National Institute of Health, USA) on SEM images. The average fiber diameter and standard deviation were calculated from 50 random measurements for each sample.

To investigate the degradation behavior of the crosslinked nanofibrous mats and Seprafilm under in vitro conditions, the samples were incubated in $5 \mathrm{ml}$ of PBS at $37^{\circ} \mathrm{C}$ for 12 , 24, 36 hours, and 2, 3, 5, 7 days. The degradation ratio (D) through the weight changes before and after immersion was calculated as [50]:

Table 1. The process parameters of the electrospun nanofibrous mats

\begin{tabular}{lccc}
\hline Parameters & HA/CMC & HA/NaAlg & HA/CMC/NaAlg \\
\hline Voltage & $20.1 \mathrm{kV}$ & $18.7 \mathrm{kV}$ & $22 \mathrm{kV}$ \\
Flow rate of the solution & $0.2 \mathrm{ml} / \mathrm{h}$ & $0.6 \mathrm{ml} / \mathrm{h}$ & $0.5 \mathrm{ml} / \mathrm{h}$ \\
Tip-to-collector distance & $9 \mathrm{~cm}$ & $7.5 \mathrm{~cm}$ & $8.5 \mathrm{~cm}$ \\
\hline
\end{tabular}


$\% \mathrm{D}=100-\left[\mathrm{W}_{\mathrm{n}} / \mathrm{W}_{0}\right] \times 100$

Where $\mathrm{W}_{0}$ is original weight (before incubation), and $\mathrm{W}_{\mathrm{n}}$ is residual dry weight on the assessment day (after incubation).

For in vitro cell adherence potential test of the crosslinked nanofibrous mats and Seprafilm, HUVEC and L-929 cells were cultured in RPMI-1640 medium supplemented with fetal calf serum (10\%), penicillin - streptomycin (50 U/ml $50 \mu \mathrm{g} / \mathrm{ml}$ ), L-glutamine (2 mM) and sodium pyruvate (1\%). Fetal Calf Serum (FCS ) is used as a supplement to basal growth medium in cell culture. When used at appropriate concentrations it supplies many specific metabolic requirements for the culture of cells. For adherent cell lines, FCS helps in attachment to the base of flask. [51, 52]

The cells were kept at $37{ }^{\circ} \mathrm{C}$ in a humidified atmosphere containing $\mathrm{CO}_{2}$ (5\%). During the test, the cells $\left(2 \times 10^{5}\right.$ cells $/ \mathrm{ml}$ ) were seeded on the samples and they could be observed on microscop after 24 hours. 300 cells were randomly selected, and the percentages of the shuttle shape cells adhered onto samples were determined. Three independent repetitions were carried out for the cell adherence test. The mean number of cells adhered per $\mathrm{cm}^{2}$ of the surface were presented.
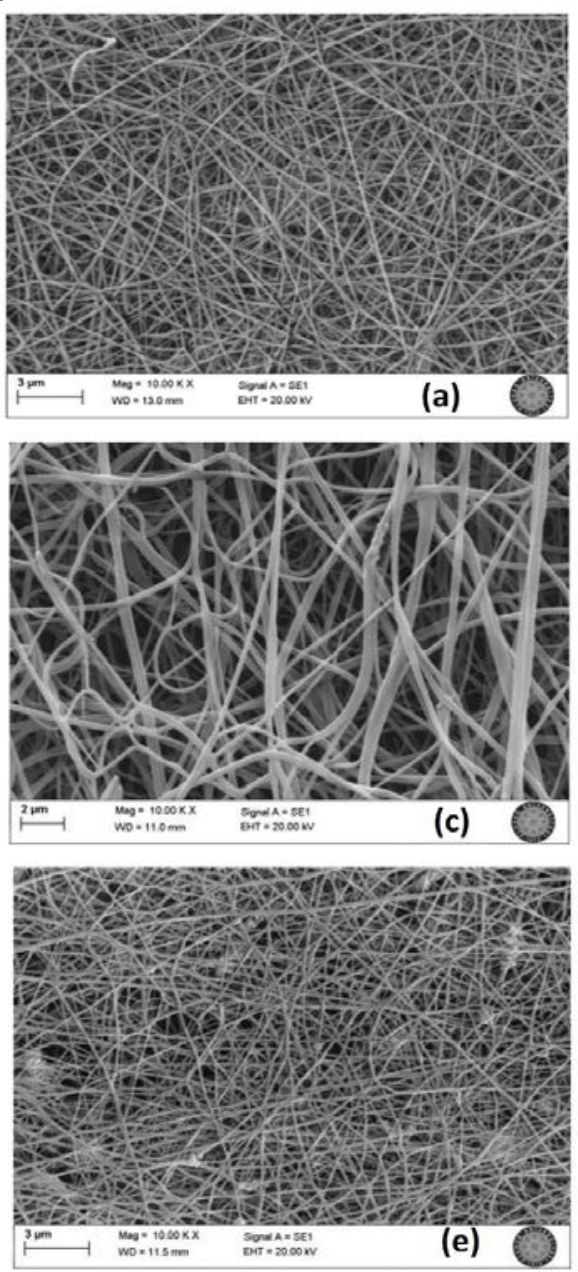

Cytotoxicity of the crosslinked nanofibrous mats and Seprafilm were carried out by the XTT cell viability test in vitro conditions according to ISO 10993-5:2010. Viability and proliferation of HUVEC and L-929 cells were determined by the absorbance measurements performed on a microplate reader at $450 \mathrm{~nm}$ and $630 \mathrm{~nm}$ after $24 \mathrm{~h}$. The test was performed three times for each sample, and the percentage cell viability was calculated by quantitative method.

The test results of cell adherence potential and cytotoxicity were evaluated statistically with Mann-Whitney U test by using SPSS 22.0 software. $\mathrm{P}<0.05$ was regarded as statistically significant.

\section{RESULTS AND DISCUSSION}

\subsection{SEM analysis}

The effect of the crosslinking process on the morphology of the nanofibrous mats was investigated with SEM analysis. SEM photographs taken with a magnification of x10000 before and after the crosslinking process are given in Figure 1.
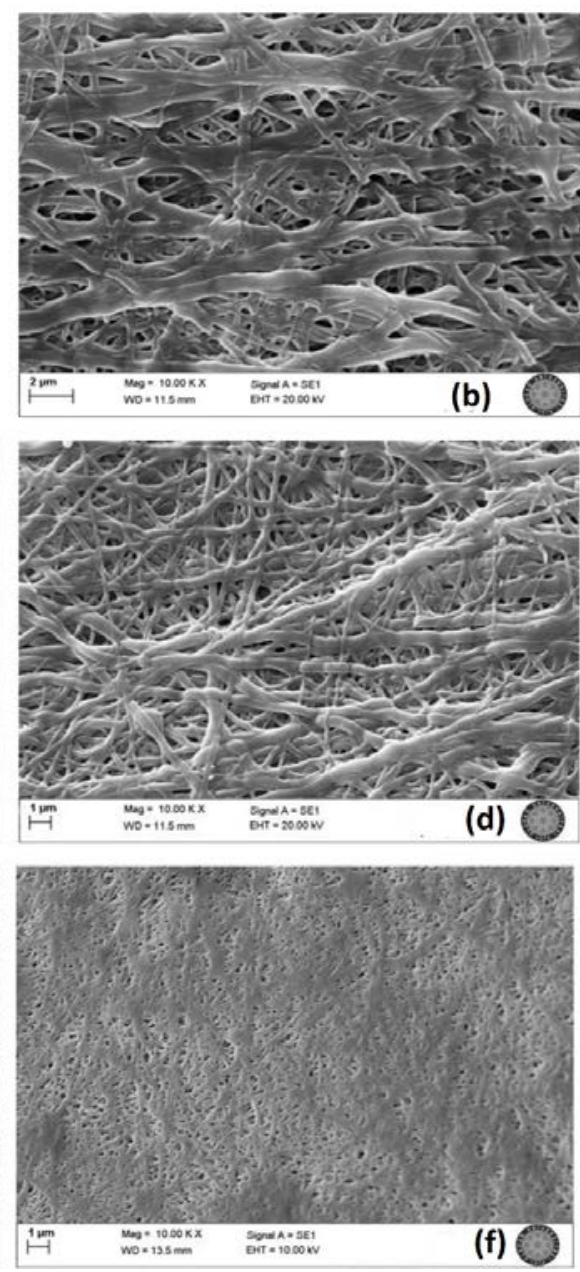

Figure 1. SEM photographs of HA/CMC (a, b), HA/NaAlg (c,d) and HA/CMC/NaAlg (e,f) nanofibrous mat; (a, c, d ) before the crosslinking process, (b,d,f) after the crosslinking process 
Before the crosslinking process, SEM photographs have shown that smooth, beadless, uniform and continuous fibers were successfully produced from HA/CMC, HA/NaAlg and $\mathrm{HA} / \mathrm{CMC} / \mathrm{NaAlg}$ polymer solutions. The average fiber diameters of the uncrosslinked HA/CMC, HA/NaAlg and $\mathrm{HA} / \mathrm{CMC} / \mathrm{NaAlg}$ nanofibrous mats were $131 \pm 46 \mathrm{~nm}$, $199 \pm 90 \mathrm{~nm}$ and $117 \pm 42 \mathrm{~nm}$, respectively.

After the crosslinking process, smooth, uniform and continuous nanofiber structure has been deteriorated. Sticking and flattening at the contact points of the fibers, and a film-like structure were observed. EDC and NHS activate the carboxyl groups in polymer molecules forming the nanofibers and ensure bond formation between hydroxyl $(-\mathrm{OH})$ and carboxyl $(-\mathrm{COOH})$ groups. The benefit of the EDC and NHS is that they do not become a part of the crosslinked structure. They just help to facilitate bonding within the crosslinked structure. New bonds cause the squeeze of the structure [49, 53]. Furthermore, the fibers collapse as flat bands, when a quantity of the solvent trapped between the fibers evaporates [54]. It is concluded that the flattening of fibers may occur owing to the rapid evaporation of the solvent, and the squeezing in the nanofibrous structure due to the formation of new bonds between polymer molecules.

In order to compare with the nanofibrous adhesion barriers, SEM image of the Seprafilm commercial adhesion barrier is given in Figure 2. When the photograph was examined, it was observed that the Seprafilm had a rough film structure and did not contain any pores.

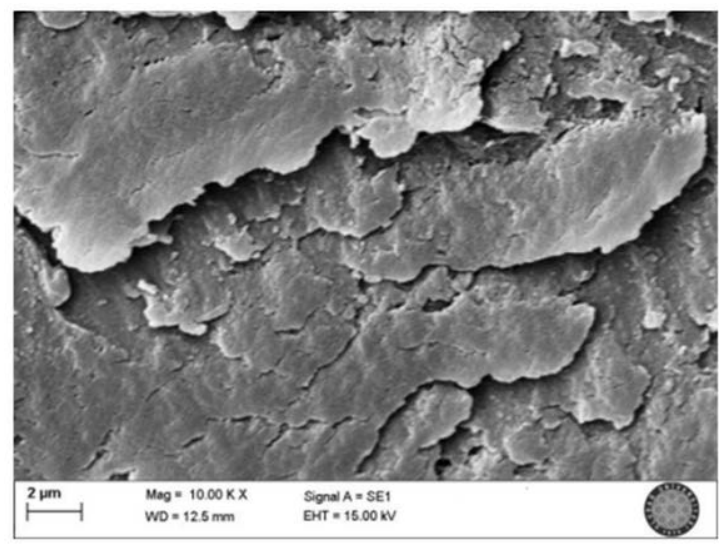

Figure 2. SEM photograph of Seprafilm

No remarkable weight loss differences between the nanofibrous mats and Seprafilm were observed within the first three days. However, the fastest degradation occurred on HA/CMC nanofibrous mat. Also, on the 5th and the 7th days, Seprafilm's degradation ratio was found to be higher than HA/NaAlg and HA/CMC/NaAlg nanofibrous mats. The reason of degradation ratio differences between nanofibrous mats might be amount of polymer differentiation. For the electrospinning process, solutions of NaAlg, CMC and HA were blended in the volume ratio of $3 / 1$
(HA/CMC), 5/1 (HA/NaAlg) and 3/1/1 (HA/CMC/NaAlg). So polymer amount of HA/CMC (1.8 g HA, $0.1 \mathrm{~g}$ CMC / $20 \mathrm{ml}$ ), HA/NaAlg (2 g HA, $0.067 \mathrm{~g}$ NaAlg) and HA/CMC/NaAlg (1.44 g HA, 0.08 g CMC, 0.08 g NaAlg) are not equal. But EDC/NHS crosslinking procedure was conducted in the same amount of crosslinking medium for all samples. EDC /NHS activate carboxyl groups in the polysaccharide molecules and forms ester bonds between the hydroxyl and carboxyl groups. The EDC/NHS is not binding to polymer molecules [49, 53]. Therefore crosslinking medium might be inadequate and crosslinking efficiency may not be equal for the samples.

\subsection{Degradation}

Figure 3 shows the weight changes in electrospun $\mathrm{HA} / \mathrm{CMC}, \mathrm{HA} / \mathrm{NaAlg}$ and $\mathrm{HA} / \mathrm{CMC} / \mathrm{NaAlg}$ crosslinked nanofibrous mats and in Seprafilm during the in vitro degradation test for a week period.

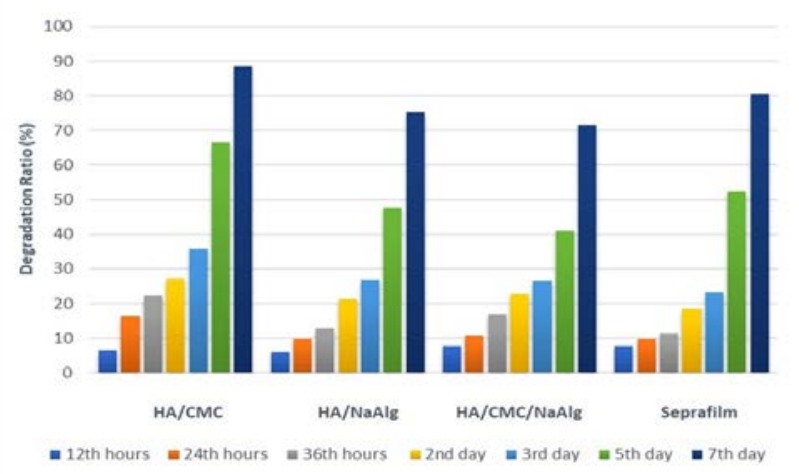

Figure 3. Degradation ratios of the crosslinked nanofibrous mats and Seprafilm

The critical period for adhesion formation is the first seven days after trauma. The mechanism of adhesion formation follows a very rapid course in this period. For this reason, an ideal surgical adhesion barrier should be able to maintain its presence by keeping the tissues separated from each other for the first seven days. However, an adhesion barrier must biodegrade rapidly in the body after the critical period for adhesion formation [55]. Consequently, it has been understood that the produced nanofibrous mats could protect their structures sufficiently during the critical healing period and could continue to separate the organs or tissues from each other.

\subsection{Cell adherence potential}

On a cell adherence potential test, adherent cells take a shuttle-like shape when they attached to the surfaces. Due to this feature of adherent cells, shuttle shaped cells on the crosslinked nanofibrous mats and Seprafilm were counted microscopically after 24 hours from seeding and the calculated percentages are presented in Table 2 . Microscopic images of the samples are also shown in Figure 4 and Figure 5. 
Table 2. The percentage of cells adhered to the surfaces after 24 hours from seeding (mean \pm standard deviation)

\begin{tabular}{ccc}
\hline Samples & HUVEC cell adherence (\%) & L929 cell adherence (\%) \\
\hline HA/CMC & $0.78 \pm 0.19$ & $0.44 \pm 0.19$ \\
HA/NaAlg & $0.56 \pm 0.51$ & $0.78 \pm 0.19$ \\
HA/CMC/NaAlg & $0.67 \pm 0.33$ & $0.44 \pm 0.51$ \\
Seprafilm & $0.78 \pm 0.19$ & $0.89 \pm 0.19$ \\
Control & $98.67 \pm 0.33$ & $99.00 \pm 0.67$ \\
\hline
\end{tabular}

*Control : No adhesion barrier
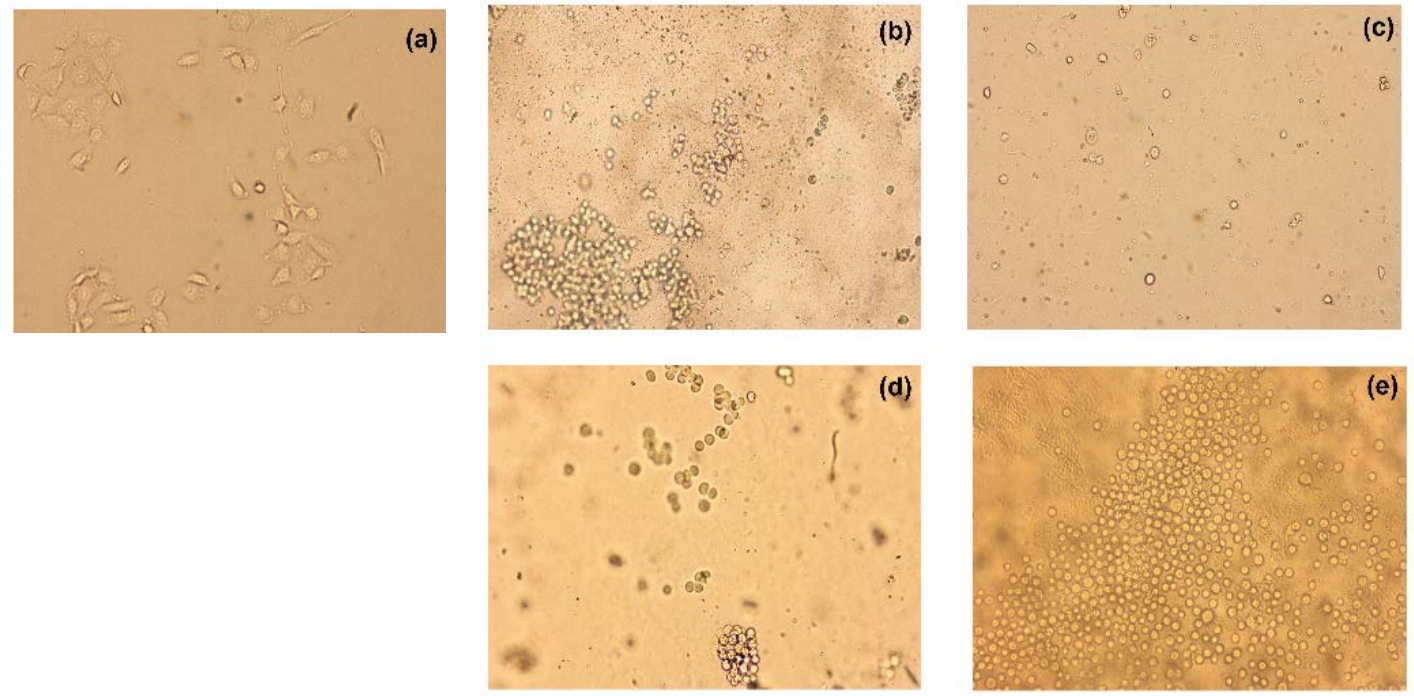

Figure 4. Microscopic images of the samples after 24 hours from seeding with HUVEC cells (X10); a) Control, b) HA/CMC, c) HA/NaAlg, d) HA/CMC/NaAlg, e) Seprafilm
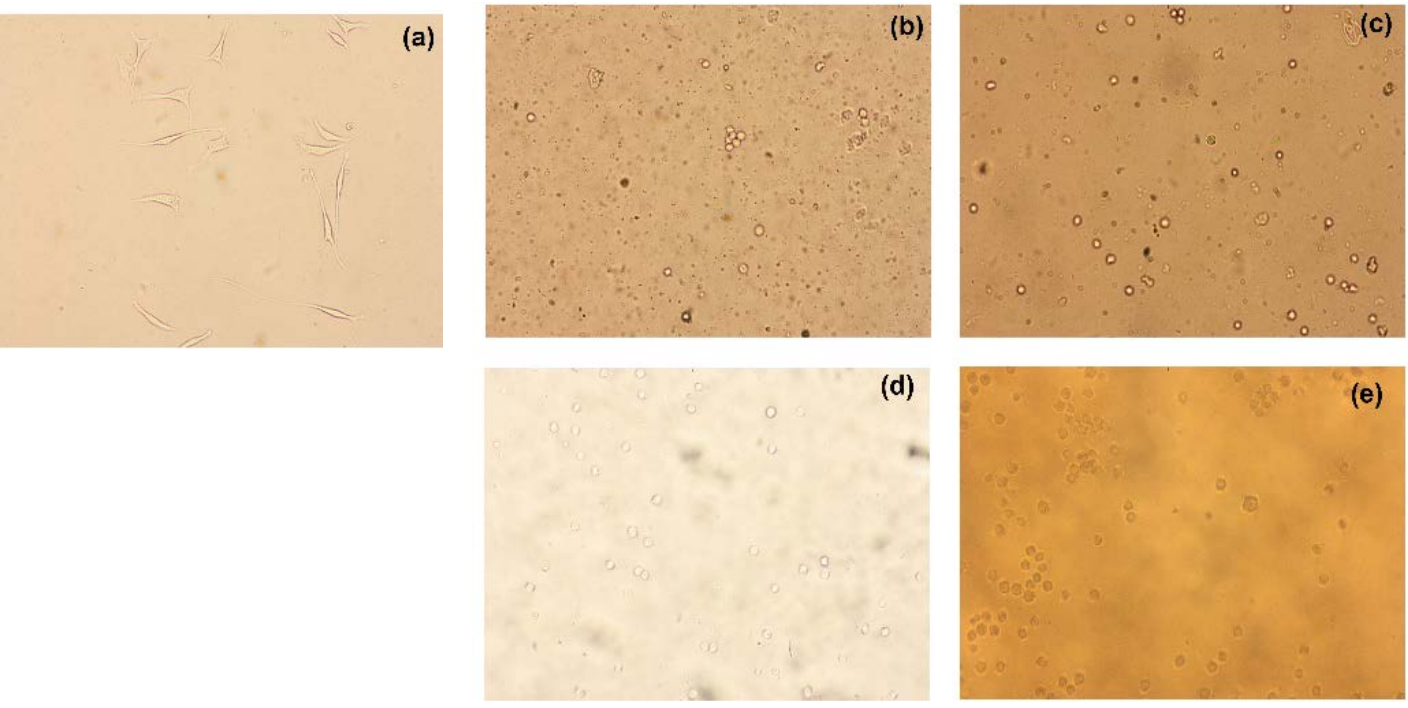

Figure 5. Microscopic images of the samples after 24 hours from seeding with L929 cells (X10); a) Control, b) HA/CMC, c) HA/NaAlg, d) HA/CMC/NaAlg, e) Seprafilm 
Cell morphology is an important identifier of adhesion behavior. If the cells adhere to the surfaces, they take the shuttle shape and become spread [56]. When the microscopic images were analyzed, it was observed that the cells did not adhere onto the nanofibrous mats and Seprafilm for both cell lines. Their cell adherence potentials were lower than $1 \%$. Whereas, cells in the control groups had shuttle shape. They adhered to the petri dishes, and they were motionless. On the other hand, cells on the nanofibrous mats and Seprafilm became round in shape. It was noticed that these cells were moving and they could not adhere to the surfaces.

When the cell adherence capacities of the nanofibrous mats and Seprafilm were compared statistically to control group for both cell lines; it was found that the percentage of cells adhered on the sample was significantly low ( $p<0.05$ ). There was no significant statistical difference between the cell adherence potentials of the nanofibrous mats and Seprafilm for both cell lines ( $\mathrm{p} \geq 0.05$ ).

Although the produced nanofibrous mats possess good biological compatibility, they were unsuitable for cell adherence. This situation is because of the hydrophilic and polyanionic surfaces do not thermodynamically support cell attachment and tissue formation [48]. Also, it has been reported that the cell attachment can be observed on the hydrophobic surfaces more than on hydrophilic surfaces $[57,58]$. Therefore, low cell adherence on the nanofibrous mats may be explained by their high hydrophilicity and their polyanionic structure which could prevent the cells to be attached. For an ideal adhesion barrier, infiltration or adherence of blood or cells should be avoided by using proper materials and by controlling precisely pore sizes [59]. It was concluded that the produced nanofibrous mats had non-adherent cell feature and could show the potential to be an ideal adhesion barrier to prevent adhesion of the tissues in the surgical operations.

\subsection{Cytotoxicity}

The ideal adhesion barrier should not have any toxic effects, and it should not have an effect on wound healing in the surgical region. Therefore, possible cytotoxic effects of the crosslinked nanofibrous mats and the commercial adhesion barrier were evaluated by using the HUVEC and L-929 cells according to XTT method. The cell viability values obtained after 24 hours were given in Table 3 .

Cell viability rates of the nanofibrous mats were determined above $90 \%$ for both of the cell lines. Furthermore, the nanofibrous mats did not show statistically any significant difference in cytotoxicity when compared with the Seprafilm and with each other $(p \geq 0.05)$.

According to ISO 10993-5:2010 standard, samples are considered as non-cytotoxic if the cell viability is above $70 \%$. To sum up, it was determined that the crosslinked nanofibrous mats had any cytotoxic effect towards to both of the cells and they could be used in surgical operations.

\section{CONCLUSIONS}

In this study, nanofibrous mats were produced as novel surgical adhesion barriers from polysaccharide-based polymers, hyaluronic acid, carboxymethyl cellulose and sodium alginate, via electrospinning process.

As CMC, HA and NaAlg used to produce the nanofibrous mats were water-soluble polymers, a crosslinking process was applied to protect their physical integrity in vitro environment. This process was performed with EDC/NHS crosslinking medium which do not have toxic effects and do not cause damage on morphological properties of the surfaces. The average fiber diameters of the uncrosslinked nanofibrous mats were obtained between 108-132 nm. After the crosslinking, the nanofibers flattened, and the average fiber diameter values increased almost doubled. On the other hand, it was seen from SEM images that Seprafilm had a rough and nonporous structure.

In the in vitro degradation test, the crosslinked nanofibrous mats and Seprafilm have suffered the weight loss in a linearly increasing manner for 7 days. While significant differences between the degradation ratios of produced nanofibrous adhesion barriers and the commercial adhesion barrier were not observed on the earlier days, the nanofibrous barriers, especially HA/NaAlg and HA/CMC/ NaAlg, kept their mass more than Seprafilm on 5th and 7th days. It was concluded that the produced nanofibrous mats could maintain their presence by keeping the tissues separate from each other during the healing process.

Table 3. The percentage cell viability (mean \pm standard deviation)

\begin{tabular}{ccc}
\hline Sample & HUVEC cell viability (\%) & L929 cell viability (\%) \\
\hline HA/CMC & $92.12 \pm 3.90$ & $97.12 \pm 6.00$ \\
HA/NaAlg & $95.45 \pm 11.00$ & $95.94 \pm 13.00$ \\
HA/CMC/NaAlg & $91.38 \pm 2.80$ & $92.54 \pm 11.00$ \\
Seprafilm & $97.29 \pm 2.10$ & $97.45 \pm 2.00$ \\
Control & $0.95 \pm 0.001$ & $0.99 \pm 0.001$ \\
\hline
\end{tabular}


In vitro cytotoxicity and cell adherence potential of the nanofiber mats and Seprafilm were evaluated with HUVEC and L-929 cells. According to the cytotoxicity test results, cell viability rates of the nanofibrous mats were determined above $90 \%$ for both cell lines. It was concluded that the produced nanofibrous mats were not cytotoxic. On the other hand, it was found that cell adherence on the nanofibrous mats was very low (below 1\%). The cell adherence potential test indicated that the produced nanofibrous mats could prevent infiltration of blood or cells.

\section{REFERENCES}

1. Deitzel J.M., Kleinmeyer J., Harris DEA., \& Tan NB. (2001). The effect of processing variables on the morphology of electrospun nanofibers and textiles. Polymer, 42,261-272.

2. Supaphol P., Suwantong O., Sangsanoh P., Srinivasan S., Jayakumar R. \& Nair SV. (2012). Electrospinning of biocompatible polymers and their potentials in biomedical applications. Advances in Polymer Science, 246,213-240.

3. Ramakrishna S., Fujıhara K., Teo WE., Lim TC. \& Ma Z. (2005). An introduction to electrospinning and nanofibers. Singapore: World Scientific Publishing Co, 396 p.

4. Huang C., Chen S., Lai C., Reneker DH., Qiu H., Ye Y. \& Hou H. (2006). Electrospun polymer nanofibres with small diameters. Nanotechnology, 17,1558-1563.

5. Li, J., Chen, Z., Zhou, M., Jing, J., Li, W., Wang, Y. \& Lee, M. (2016). Polyoxometalate-Driven Self-Assembly of Short Peptides into Multivalent Nanofibers with Enhanced Antibacterial Activity. Angewandte Chemie International Edition, 55(7), 2592-2595.

6. Tan, C., Qi, X., Liu, Z., Zhao, F., Li, H., Huang, X. \& Tang, Z. (2015). Self-assembled chiral nanofibers from ultrathin lowdimensional nanomaterials. Journal of the American Chemical Society, 137(4), 1565-1571.

7. Liu, Y., Yan, X., Lan, J., Yu, Y., Yang, X., \& Lin, Y. (2017). Phaseseparation induced hollow/porous carbon nanofibers containing in situ generated ultrafine $\mathrm{SnO} \mathrm{x}$ as anode materials for lithium-ion batteries. Materials Chemistry Frontiers 1(7), 1331-1337.

8. Katsogiannis, K. A. G., Vladisavljević, G. T., \& Georgiadou, S (2015). Porous electrospun polycaprolactone (PCL) fibres by phase separation. European Polymer Journal., 69, 284-295.

9. Yan, C., Chen, G., Zhou, X., Sun, J., \& Lv, C. (2016) Template-Based Engineering of Carbon-Doped Co3O4 Hollow Nanofibers as Anode Materials for Lithium-Ion Batteries. Advanced Functional Materials 26(9), 1428-1436.

10. Mishra, S., \& Verma, N. (2016). Carbon bead-supported hollow carbon nanofibers synthesized via templating method for the removal of hexavalent chromium. Journal of Industrial and Engineering Chemistry. 36, 346-354

11. Laurencin, C. T., Kumbar, S. G., Nukavarapu, S. P., James, R., \& Hogan, M. V. (2008). Recent patents on electrospun biomedical nanostructures: an overview. Recent Patents on Biomedical Engineering, 68-78.

12. Eatemadi, A., Daraee, H., Zarghami, N., Melat Yar, H., \& Akbarzadeh, A. (2016). Nanofiber: synthesis and biomedical applications: Artificial Cells, Nanomedicine, and Biotechnology, 44(1), 111-121.

13. Sharma, J., Lizu, M., Stewart, M., Zygula, K., Lu, Y., Chauhan, R., \& Wei, S. (2015). Multifunctional nanofibers towards active biomedical therapeutics. Polymers, 7(2), 186-219.

14. Khalil, K. A., Fouad, H., Elsarnagawy, T., \& Almajhdi, F. N. (2013). Preparation and characterization of electrospun PLGA/silver composite nanofibers for biomedical applications. Reklamlar International Journal of Electrochemistry, 8(3), 3483-3493.
The cytotoxicity, cell adherence and degradation behaviors under in vitro conditions showed that the crosslinked nanofibrous mats are have potentials to use as adhesion barriers.

\section{ACKNOWLEDGMENTS}

The authors thank to TUBITAK (The Scientific and Technical Research Council of Turkey) for its financial support in the research project (No. 214M415).

15. Şafak Ş., Düzyer Ş. \& Karaca E. (2016). Evaluation of biocompatibility of fibroin-based electrospun nanofibrous mats for medical applications. Industria Textila, 67,3-9.

16. Rim, N. G., Shin, C. S., \& Shin, H. (2013). Current approaches to electrospun nanofibers for tissue engineering. Biomedical Materials, 8(1), 014102.

17. Shelke N.B., James R., Laurencin C.T. \& Kumbar S.G. (2014). Polysaccharide biomaterials for drug delivery and regenerative engineering. Polymers for Advanced Technologies, 25,448-460.

18. Kusindarta, D. L., \& Wihadmadyatami, H. (2018). The Role of Extracellular Matrix in Tissue Regeneration. Tissue Regeneration, 65.

19. Theocharis, A. D., Skandalis, S. S., Gialeli, C., \& Karamanos, N. K. (2016). Extracellular matrix structure. Advanced Drug Delivery Reviews, 97, 4-27.

20. Abedin, M., \& King, N. (2010). Diverse evolutionary paths to cell adhesion. Trends in Cell Biology. 20(1), 734-742.

21. Varki, A., Cummings, R., Esko, J., Freeze, H., Hart, G., \& Marth, J. (1999). Proteoglycans and glycosaminoglycans. In Essentials of glycobiology. Cold Spring Harbor Laboratory Press.

22. Zhang, F., Zhang, Z., \& Linhardt, R. J. (2010). Glycosaminoglycans. In Handbook of glycomics. Academic Press, pp. 59-80.

23. Rowley, J. A., Madlambayan, G., \& Mooney, D. J. (1999). Alginate hydrogels as synthetic extracellular matrix materials. Biomaterials, 20(1), 45-53.

24. Ji Y., Ghosh K., Li B., Sokolov J.C., Clark R.A. \& Rafailovich M.H. (2006). Dual-syringe reactive electrospinning of cross-linked hyaluronic acid hydrogel nanofibers for tissue engineering applications. Macromolecular Bioscience, 6,811-817.

25. Schante C.E., Zuber G., Herlin C. \& Vandamme T.F. (2011). Chemical modifications of hyaluronic acid for the synthesis of derivatives for a broad range of biomedical applications. Carbohydrate Polymers, 85, 469-489.

26. Aytar P., Buruk Y. \& Çabuk A. (2013). Streptecoccus equi ile hyaluronik asit üretiminde optimum koşullarin plackett-burman yöntemi ile belirlenmesi. Elektronik Mikrobiyoloji Dergisi, 11, 2835.

27. Collins M.N. \& Birkinshaw C. (2013). Hyaluronic acid based scaffolds for tissue engineering-a review. Carbohydrate Polymers

28. Qiu X. \& Hu S. (2013). Smart materials based on cellulose: a review of the preparations, properties and applications. Materials, 6, 738781.

29. Klemm D., Heublein B., Fink H.P. \& Bohn A. (2005). Cellulose: fascinating biopolymer and sustainable raw material. Angewandte Chemie International Edition, 44, 3358-3393.

30. Qin Y. (2008). Alginate fibres: an overview of the production processes and applications in wound management. Polymer International, 57, 171-180. 
31. Üstündağ C.G., Karaca E., Özbek S. \& Çavuşoğlu İ. (2010). In vivo evaluation of electrospun poly (vinyl alcohol)/sodium alginate nanofibrous mat as wound dressing. Tekstil Konfeksiyon, 20, 290-298.

32. Şahiner İ.T. (2011). Simvastatin yüklü polipropilen yama ile onarilan karın duvarı defektlerinde batın içi yapışıklıkların karşılaştırılması. Ph.D. Dissertation: Kırıkkale University.

33. Yeğenoğlu A. (2005). Postoperatif intraperitoneal adezyonların önlenmesinde değişik dozlardaki heparin ve seprafilm'in etkinliklerinin karşılaştırılması. Ph.D. Dissertation: Dr. Lütfi Kırdar Education and Research Hospital.

34. Günaydın M., Güvenç D., Yıldız L., Aksoy A., Tander B., Bıçakcı Ü., Ayyıldız H.S., Sünter A.T. \& Bernay F. (2012). Comparison of substances used for prevention of intra-abdominal adhesions: an experimental study in rats. International Journal of Medical Sciences, 32, 337-345.

35. Şafak Ş. (2016). Investigation of usage performance of electrospun nanofibrous mats produced from biodegradable polymers as surgical adhesion barrier. Ph.D. Dissertation: Uludag University.

36. Zong X., Li S., Chen E., Garlick B., Kim K.S., Fang D. \& Chu B. (2004). Prevention of postsurgery-induced abdominal adhesions by electrospun bioabsorbable nanofibrous poly (lactide-co-glycolide)based membranes. Annals of Surgery, 240, 910-915.

37. Dinarvand P., Hashemi S.M., Seyedjafari E., Shabani I., Mohammadi-Sangcheshmeh A., Farhadian S. \& Soleimani M. (2012). Function of poly (lactic-co-glycolic acid) nanofiber in reduction of adhesion bands. Journal of Surgical Research, 172, 1-9.

38. Chang J.J., Lee Y.H., Wu M.H., Yang M.C. \& Chien C.T. (2012) Electrospun anti-adhesion barrier made of chitosan alginate for reducing peritoneal adhesions. Carbohydrate Polymers, 88, 1304 1312 .

39. Shi R., Xue J., Wang H., Wang R., Gong M., Chen D. \& Tian W. (2015). Fabrication and evaluation of a homogeneous electrospun PCL-gelatin hybrid membrane as an anti-adhesion barrier for craniectomy. Journal of Materials Chemistry B, 3, 4063-4073.

40. Lee Y.W., Chu B., Lee Y.G., Kim N.H., Kim J.H., Kim K.I. \& Kwon S.W. (2009). Efficacy and safety of the electrospun nanofibrous adhesion barrier for laparoscopic surgery in a rabbit model. Journal of the Korean Surgical Society, 76, 73-80.

41. Bölgen N., Vargel I., Korkusuz P., Menceloğlu Y.Z. \& Pişkin E. (2007). In vivo performance of antibiotic embedded electrospun PCL membranes for prevention of abdominal adhesions. Journal of Biomedical Materials Research Part B, 81, 530-543.

42. Adegani J.F., Seyedjafari E., Gheibi N., Soleimani M. \& Sahmani M. (2016). Prevention of adhesion bands by ibuprofen-loaded PLGA nanofibers. Biotechnological Programme, 32, 990-997.

43. Shin Y.C., Yang W.J., Lee J.H., Oh J.W., Kim T.W., Park J.C., Hyon S.H. \& Han D.W. (2014). PLGA nanofiber membranes loaded with epigallocatechin-3-O-gallate are beneficial to prevention of postsurgical adhesions. International Journal of Nanomedicine, 9, 4067-4078.

44. Chen C.H., Chen S.H., Shalumon K.T. \& Chen J.P. (2015). Dual functional core-sheath electrospun hyaluronic acid/polycaprolactone nanofibrous membranes embedded with silver nanoparticles for prevention of peritendinous adhesion. Acta Biomaterialia, 26, 225235.

45. Şafak Ş. \& Karaca E. (2017). Production and crosslinking of polysaccharide based nanofibrous mat for biomedical applications. Uludag University JFE, 22, 127-144.
46. Fischer R.L., McCoy M.G. \& Grant S.A. (2012). Electrospinning collagen and hyaluronic acid nanofiber meshes. Journal of Materials Science: Materials in Medicine, 23, 1645-1654.

47. Lu P.L., Lai J.Y., Ma D.H.K. \& Hsiue G.H. (2008). Carbodiimide cross-linked hyaluronic acid hydrogels as cell sheet delivery vehicles: characterization and interaction with corneal endothelial cells. Journal of Biomaterials Science Polymer Edition, 19, 1-18.

48. Xu S., Li J., He A., Liu W., Jiang X., Zheng J., Han C.C., Hsiao B.S., Chu B. \& Fang D. (2009). Chemical crosslinking and biophysical properties of electrospun hyaluronic acid based ultra-thin fibrous membranes. Polymer, 50, 3762-3769.

49. Tomihata K, \& Ikada Y. (1997). Crosslinking of hyaluronic acid with water-soluble carbodiimide. Journal of Biomedical Material Research, 37, 243-251.

50. Fouad, H., Elsarnagawy, T., Almajhdi, F. N., \& Khalil, K. A. (2013). Preparation and in vitro thermo-mechanical characterization of electrospun PLGA nanofibers for soft and hard tissue replacement. International Journal of Electrochemical Science, 8(2), 2293-2304.

51. Biological Industries. (2019, September, 17), Introduction to Fetal Bovine Serum Class. Retrieved from https://www.bioind.com/ worldwide/support/tech-tips-posters/introduction-to-fetal-bovineserum-class/

52. Brunner, D., Frank, J., Appl, H., Schöffl, H., Pfaller, W., \& Gstraunthaler, G. (2010). The serum-free media interactive online database. ALTEX-Alternatives to animal experimentation, 27, 53-62.

53. Sinha M.K., Das B.R., Srivastava A. \& Saxena A.K. (2013) Needleless electrospinning and coating of poly vinyl alcohol with cross-linking agent via in-situ technique. International Journal of Textile and Fashion Technology, 3, 29-38.

54. Baji A., Mai Y.W., Wong S.C., Abtahi M. \& Chen P. (2010). Electrospinning of polymer nanofibers: effects on oriented morphology, structures and tensile properties. Composites Science and Technology, 70, 703-718.

55. Hatipoğlu E. (2011). Ameliyat sonrası karın içi yapışıklıkların önlenmesinde sodyum hyaluronat karboksimetilselüloz membran, polietilen glikol - lysine ve hyaluronik asitin etkinliğinin wistar albino tipi sıçanlarda yapılan deneysel çalışma ile araştırılması. Ph.D. Dissertation: Istanbul University.

56. Ma Z., Kotaki M., Yong T., He W. \& Ramakrishna S. (2005). Surface engineering of electrospun polyethylene terephthalate (PET) nanofibers towards development of a new material for blood vessel engineering. Biomaterials, 26,2527-2536.

57. Yang D.J., Chen F., Xiong Z.C., Xiong C.D. \& Wang Y.Z. (2009). Tissue anti-adhesion potential of biodegradable PELA electrospun membranes. Acta Biomaterials, 5, 2467-2474.

58. Lee J.H., Lee S.J., Khang G. \& Lee H.B. (2000). The effect of fluid shear stress on endothelial cell adhesiveness to polymer surfaces with wettability gradient. Journal of Colloid and Interface Science, 230, 84-90

59. Mayes S., Schmidth C.E. \& Peterson D. (2012). Anti-adhesive barrier membrane using alginate and hyaluronic acid for biomedical aplications. Patent 0088832- A1, USA 